Article

\title{
Entrepreneurship Intentions Analysis of Mexican University Students Using an Artificial Neural Network to Promote Sustainable Businesses: An Interdisciplinary Perspective
}

\author{
Josué Aarón López-Leyva ${ }^{1, *}\left(\mathbb{D}\right.$, Miguel Ángel Ponce-Camacho ${ }^{2}$, Alfredo Valadez-García ${ }^{3}$, \\ Víctor Manuel Ramos-García ${ }^{4}$ and Hania Nered Mena-Ibarra ${ }^{5}$ \\ 1 Centro de Innovación y Diseño, CETyS Universidad, Ensenada 22860, Mexico \\ 2 Centro de Innovación y Diseño, CETyS Universidad, Mexicali 21259, Mexico; miguel.ponce@cetys.mx \\ 3 Escuela de Administración y Negocios, CETyS Universidad, Tijuana 22210, Mexico; alfredo.valadez@cetys.mx \\ 4 Departamento de Física, Matemáticas e Ingeniería, Universidad de Sonora, Navojoa 85880, Mexico; \\ victor.ramos@navojoa.uson.mx \\ 5 Departamento de Psicología, Universidad Samann de Jalisco, Guadalajara 44600, Mexico; \\ hmena.docente@usj.edu.mx \\ * Correspondence: josue.lopez@cetys.mx
}

check for updates

Citation: López-Leyva, J.A.; Ponce-Camacho, M.Á.;

Valadez-García, A.; Ramos-García,

V.M.; Mena-Ibarra, H.N.

Entrepreneurship Intentions Analysis of Mexican University Students Using an Artificial Neural Network to Promote Sustainable Businesses: An Interdisciplinary Perspective. Sustainability 2022, 14, 2280. https:// doi.org/10.3390/su14042280

Academic Editor: Mário José Baptista Franco

Received: 27 January 2022

Accepted: 12 February 2022

Published: 17 February 2022

Publisher's Note: MDPI stays neutral with regard to jurisdictional claims in published maps and institutional affiliations.

Copyright: (C) 2022 by the authors. Licensee MDPI, Basel, Switzerland. This article is an open access article distributed under the terms and conditions of the Creative Commons Attribution (CC BY) license (https:// creativecommons.org/licenses/by/ $4.0 /)$.

\begin{abstract}
This paper shows an analysis of the entrepreneurship intentions patterns in the short, medium, and long term of Mexican university students. The entrepreneurship patterns analysis was carried out using a customized artificial neural network considering as inputs the self-assessment of multiple intelligences from an interdisciplinary perspective. Thus, many important findings reveal that not all multiple intelligences have a direct and proportional impact on entrepreneurship intention. In fact, Linguistic-Verbal Intelligence, Intrapersonal Intelligence, and Interpersonal intelligence are the types of intelligence that have the greatest influence on entrepreneurial intentions. In addition, the performance metrics of the ANN for classifying the entrepreneurship intentions are higher than the ones reported in the literature (i.e., accuracy $\approx 99.29 \%$, precision $\approx 98.89 \%$, sensitivity $\approx 99.53 \%$, and specificity $\approx 99.01 \%$ ). The paper contributes to the literature on the deep understanding of entrepreneurs' behavior concerning the strengths and weaknesses of their multiple intelligences. Besides, this interdisciplinary empirical work contributes to improving the design of methods and techniques to strengthen entrepreneurship from the earliest stages of students' lives and promote sustainable businesses. The most surprising finding was the minimal relationship of Naturalistic Intelligence to undertake sustainable and robust projects, which demands more detailed and in-depth analysis. Finally, some proposals are presented to improve the teaching process of entrepreneurship and sustainability, considering the artificiality, sustainability, and entrepreneurship involved in academic programs at universities.
\end{abstract}

Keywords: entrepreneurship intention; multiple intelligence; study program innovation; entrepreneurship education challenges; technology applied

\section{Introduction}

Nowadays, entrepreneurship is an activity and lifestyle, as well as professional training, which is an important part of the development of society. In general, entrepreneurship at any level (i.e., local, regional, national, or international), and regardless of the purpose of the entrepreneurship (i.e., related to a process, service, or product), greatly helps the development of companies and people [1-3]. However, on many occasions entrepreneurship actions, rather, teaching and training related to entrepreneurship, do not achieve the objectives and goals set; that is, there are many options for the development of the entrepreneur, whether it be related to academic training or external courses, among others. However, all of this cannot ensure, in any way, the success of entrepreneurial projects, 
which we can define, for example, as technology-based startups or the generation of direct and indirect jobs, among others $[4,5]$. Considering the above, entrepreneurship can also be considered a process that, when not planned and managed properly, can become unsustainable. That is, there is a large number of invested resources (time, people, money, institutions, programs, etc.) in the entrepreneurship process, and even so, the desired results are not fully achieved [6,7]. Indeed, sometimes the negative impact becomes evident when too much investment and too few results related to entrepreneurship cause discouragement in the institutions and, therefore, reduce overall support for the development of entrepreneurs [8-10]. In this way, this unsustainable process (i.e., non-robust process) apparently has relevant benefits, but in the medium and long term, there is no evidence of the true competitive advantages of the region or institution that carries out the entrepreneurship process [11].

On the other hand, formal teaching processes related to entrepreneurship, for example, university academic programs, often only consider, at a very low level, aspects related to entrepreneurship. As a matter of fact, the creation of such academic plans at times lacks sufficient and solid arguments for the establishment of certain subjects, themes, and extracurricular activities that can significantly help the entrepreneurship process in a broadly sustainable sense $[12,13]$. Considering the aforementioned, the fact that a university student finds topics related to entrepreneurship does not imply, in any way, a minimum intention to carry out entrepreneurial actions. So, why is entrepreneurship not a sustainable process in the short, medium, or long term? Which factors cause non-sustainability? A potential answer could be the entrepreneurial relationship of university students with different personal variables, family situation, or academic history, among others [14-16]. That is, not all people perceive and understand in the same way the techniques, concepts, and tools related to entrepreneurship, due to personal aspects that prevent them from sustainably developing an entrepreneurship process.

From a psychological point of view, the theory of multiple intelligences can help to describe people's strengths and weaknesses [17,18]. In fact, occasionally some aspects of the mindset of an entrepreneur have been analyzed using some concepts related to emotional intelligence [19]. However, the analysis tools used are conventional and belong to a discipline. In addition, the analysis logic also belongs to a discipline, which does not allow us to fully understand the relationship of multiple intelligences with the intention of entrepreneurship. In our case, we used a machine learning tool to discover entrepreneurship patterns [20].

Regarding the concept of sustainability, it is highly important to clarify the two ways in which this concept can be understood and applied to the intention of entrepreneurship. The first way is the most obvious and traditional, and it simply involves starting a business or company, whether related to a product, service, or process, among other innovations, with outcomes that are related to sustainability (i.e., environmental care). The second way is not as obvious, and is perhaps the most complicated to assimilate. It implies that the entrepreneurship process is robust and sustainable (i.e., related to sustainable development). In this sense, all the stages, processes, and activities used since the creation of the idea until the last stage of innovation belong to a robust, sustainable, strengthened, and well-defined entrepreneurship system with proven results (which is not the full reality in many of the entrepreneurial processes around the world). Considering the above, both ways of distinguishing the concept of sustainability will be holistically analyzed in this work, i.e., it will allow students to assimilate the concept in the best way [21-23]. In particular, the hypothesis that this paper presents is the relationship of the entrepreneurial intentions in the short, medium, and long term of university students with the multiple intelligences of each student [24-27]. Given the above, the interdisciplinary perspective (using techniques and reasoning typical of the area of engineering, psychology, and business management) to analyze the intentions of entrepreneurship is extremely useful. After the literature review, various works were found that analyze emotional intelligence and entrepreneurial attitudes and intentions through various methods, tools, and theories 
(e.g., survey questionnaire or planned behavior theory, among others) considering both public and private educational institutions, different educational levels, and locations around the world, since entrepreneurial intentions also depend on other factors [28-33]. Regarding the entrepreneurship intention predictions based on the machine learning approach, some works allow the use of engineering tools and methods in other areas of knowledge to be established, such as entrepreneurship and psychology. The foregoing implies that the use of machine learning tools related to entrepreneurial intention is not so controversial [20,34-36].

This paper is organized as follows. Section 2 describes the different multiple intelligences according to Gardner's theory, and some precisions and analyses regarding multiple intelligences are presented. Section 3 presents the method and analysis tools to determine the intention of entrepreneurship in the short, medium, and long term of university students. Then, Section 4 presents some relevant results that allow aspects that could affect the sustainability of the entrepreneurship process to be identified. Next, Section 5 describes some important findings regarding the sustainability of the entrepreneurship process and multiple intelligences. Finally, Section 6 presents the conclusion of the paper.

\section{Multiple Intelligences and Their Relationship with Entrepreneurship}

\subsection{Multiple Intelligences Theory}

Because this paper addresses an interdisciplinary problem, it is necessary to define some concepts and tools that belong to different disciplines. Firstly, from the point of view of psychology as a discipline, we can mention that a person (in this case, a university student) possesses a variety of intelligence, as Gardner's model of multiple intelligences explains. Thus, the multiple intelligences theory proposes the following types of intelligence: Logical-Mathematical Intelligence (MI1), Linguistic-Verbal Intelligence (MI2), Visual-Spatial Intelligence (MI3), Musical Intelligence (MI4), Bodily-Kinesthetic Intelligence (MI5), Intrapersonal Intelligence (MI6), Interpersonal Intelligence (MI7), and Naturalistic Intelligence (MI8) [37-39]. It is not within the scope of this paper to describe and analyze these intelligences in depth. However, it is imperative to mention the potential relationship that exists between multiple intelligences and the diverse actions of people, among them those related to the intention and capacity of entrepreneurship in the short, medium, and long term of university students [40,41]. On the other hand, analyzing multiple intelligences concerning the sustainability of entrepreneurial processes presents important advantages, among which we can mention the following:

$\checkmark \quad$ It motivates the person to carry out entrepreneurial activities outside a strict teaching framework; that is, their multiple intelligences are used to catalyze the motivation of the sustainable entrepreneurship process.

$\checkmark \quad$ Learning can be personalized related to sustainability and entrepreneurship based on the particular perceptions of students.

$\checkmark \quad$ It facilitates people's attention about topics, terms, and techniques of general and specific use in the field of entrepreneurship and sustainability.

$\checkmark \quad$ It offers more complete and real learning concerning what sustainability and entrepreneurship mean in the personal context of the student.

$\checkmark \quad$ It is possible to develop many skills and abilities that are related to the success of a sustainable entrepreneurial project.

$\checkmark \quad$ It encourages unlimited creativity and invites innovation concerning sustainable entrepreneurial projects-for example, the invention of a product, process, or service with a real social impact.

Even with the above, for various authors in the area of psychology, the use of Gardner's model of multiple intelligences is unfortunate in all senses, because, as its name says, it is only a theory, and there are no empirical data that can verify the mentioned classification and is widely regarded as being seriously flawed [42-44]. Nonetheless, in general, the theory of multiple intelligences is still being investigated and applied to different 
education models, including those related to sustainability and entrepreneurship. Indeed, the intention of this paper is to generate empirical data related to this intelligences model.

\subsection{Background of Entrepreneurship Patterns}

Entrepreneurship patterns are, in general, a quantitative indicator that relates the particular characteristics of an entrepreneur to the level (to put it in a certain way) of each multiple intelligence they possess. In particular, both the intention of entrepreneurship in the short, medium, and long term and the real entrepreneurial activity of university students can be related to certain patterns related to their multiple intelligences. In addition, and more importantly, there are also potential relationships that determine certain patterns between multiple intelligences and the nature of sustainability, not only in entrepreneurial projects but also in the professional life of each person. For pattern recognition, many technological and mathematical options can help. Pattern recognition techniques first use a learning or training stage where the system is taught the information (objects, signals, or data, among others) that it must take as a pattern. The second stage is the determination of learned patterns immersed in a data set larger than the pattern itself. In general, pattern recognition techniques can be categorized into six parts, including statistical techniques, structural techniques, template matching, neural network approach, fuzzy model, and hybrid models [45-48].

Regarding the use of the neural network approach or artificial neural networks (ANN), a huge data set is necessary for training. In our case, a population of 1000 university students at the national level (Mexico) from different universities were surveyed to obtain a self-assessment of the multiple intelligences of each person, as well as the intention of entrepreneurship in the short, medium, and long term. In particular, Table 1 shows the descriptive statistics of the data set used, considering the most important characteristics.

Table 1. Descriptive statistics.

\begin{tabular}{cccc}
\hline Characteristics & Frequency & Unit & \% \\
\hline Total participant population & 1000 & People & 100 \\
Female participation & 541 & People & 54.1 \\
Male participation & 459 & People & 45.9 \\
Age of participants (median) & 21 & People & - \\
Engineering students & 256 & People & 26.6 \\
Administration and business students & 413 & People & 41.3 \\
Social and humanities students & 331 & People & 33.1 \\
\hline
\end{tabular}

A very important aspect to clarify is that the survey was applied during the year 2020, that is, during the COVID-19 pandemic, so the responses and entrepreneurship intentions are highly related to the different digital tools used during the pandemic and also to the collaborative behavior in digital entrepreneurship. Since the technical aspects related to ANN are not within the scope of this manuscript, preference will be given to the results and findings obtained related to the main idea of the manuscript. However, important references are shared concerning the bases and applications of ANN in different areas of knowledge (AOKs) [49-51]. In general, Figure 1 shows the artificial neural network diagram, where it can be seen that the input variables were the self-assessment of the multiple intelligences and the output variables were the entrepreneurial intention. The diagram also shows the input layer, the 30 hidden layers used (this parameter can be modified to improve the classifier performance), and the output layer. Other technical details of the ANN are not shown. Taking into account the aforementioned, it can be said that the use of the ANN in conjunction with an analysis of multiple intelligences to determine entrepreneurship patterns is related to the concept of artificiality. This is because an attempt was made to synthesize the reasons for entrepreneurship considering multiple intelligences in a hypothetical scenario to modify future results in the real world (sustainable real entrepreneurship actions that generate value to society) by modeling the 
known variables. In this case, the intention of entrepreneurship in the short, medium, and long term was shared by the students, as well as the scores of the self-evaluation related to multiple intelligences [52,53].

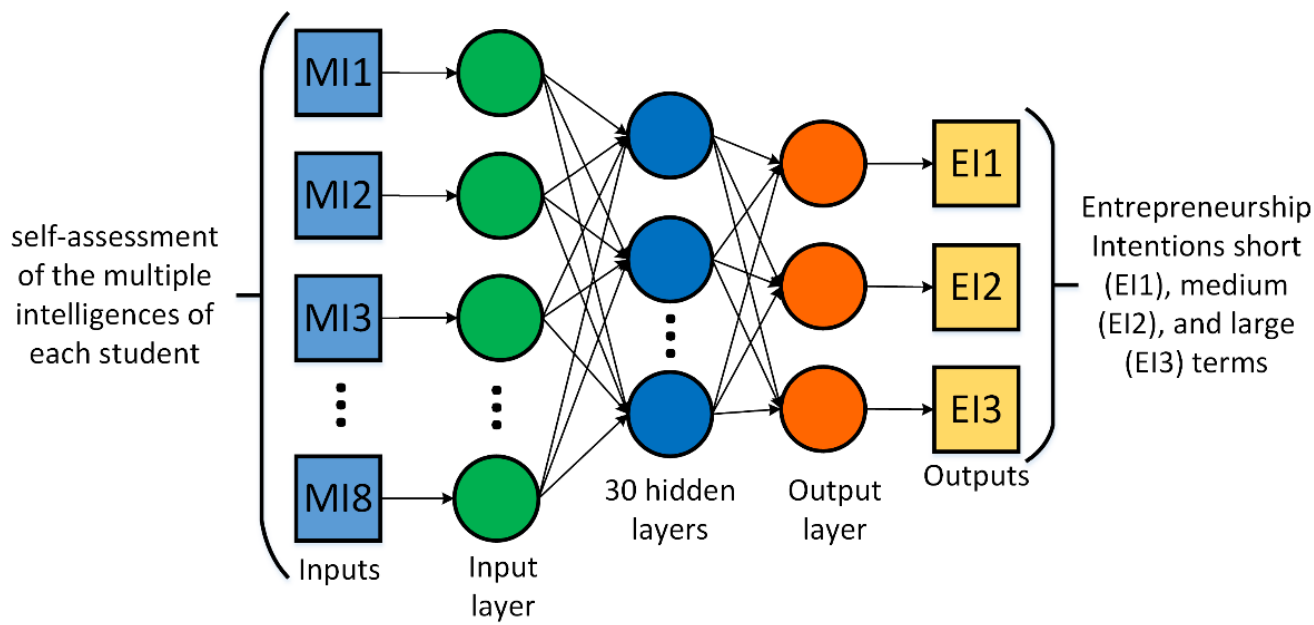

Figure 1. Artificial neural network diagram.

\section{Overall Results and Determination of Entrepreneurship Intention}

The general results of the survey are shown below. Figure 2 shows short-term entrepreneurship intentions. A total of $41.3 \%$ of the students intended to start an entrepreneurial project with a sustainable focus, i.e., an entrepreneurial project seeking a balance between the environmental, social, and economic aspects, in addition to planning a long-term project. On the other hand, 30.6\% had doubts about it. Finally, 28.1\% did not have an intention of entrepreneurship in the short term. In this case, the result of students who had doubts about starting a sustainable entrepreneurial project (30.6\%) is interesting, because the data collection instrument also helped to determine the lack of knowledge about the concept of sustainability.

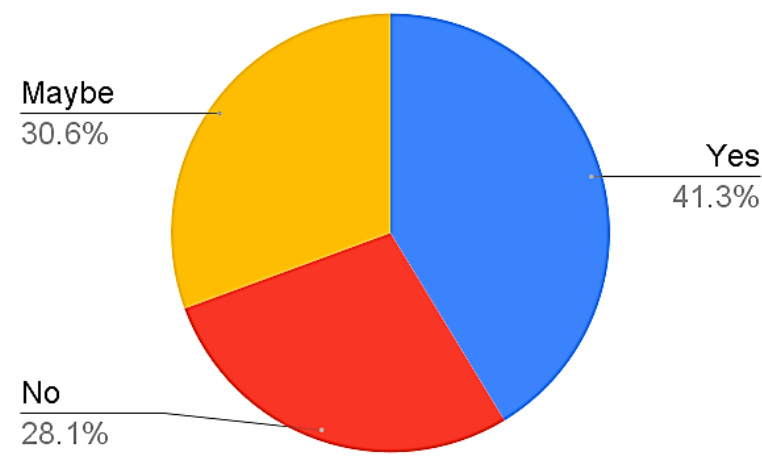

Figure 2. Short-term entrepreneurship intention.

Figure 3 shows the results of the entrepreneurship intention in the medium term. In this case, it is remarkable how many students intended to start an entrepreneurial project (73.6\%). On the other hand, 6.5\% did not have an intention to undertake an entrepreneurial project. Particularly interesting is the change in entrepreneurship interest between the short and medium term, which will be analyzed in Section 4. In addition, it is also striking that the percentage of students who did not have the intention or who had doubts about starting a sustainable entrepreneurial project decreased compared to short-term entrepreneurship intention. 


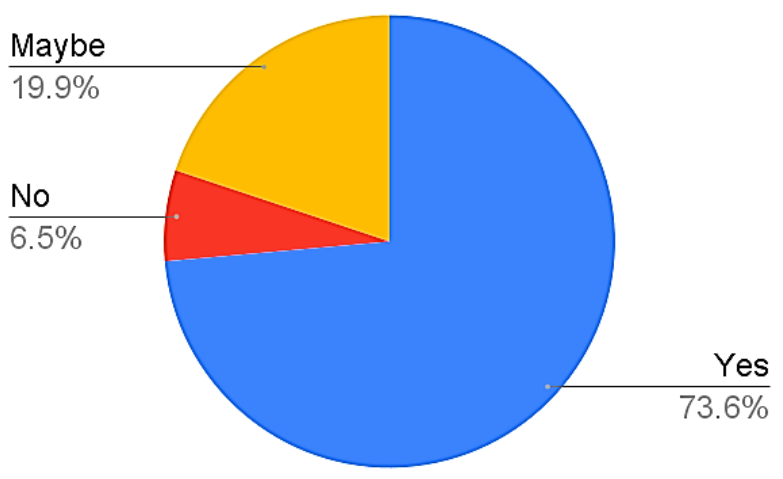

Figure 3. Medium-term entrepreneurship intention.

Next, Figure 4 shows the result of long-term entrepreneurship intention. In particular, $92.2 \%$ of university students had the intention of long-term entrepreneurship. Considering the aforementioned results, a pattern in the long term can be appreciated; that is, there were quite a few doubts regarding entrepreneurship in the short and medium term, and students preferred long-term analysis and planning.

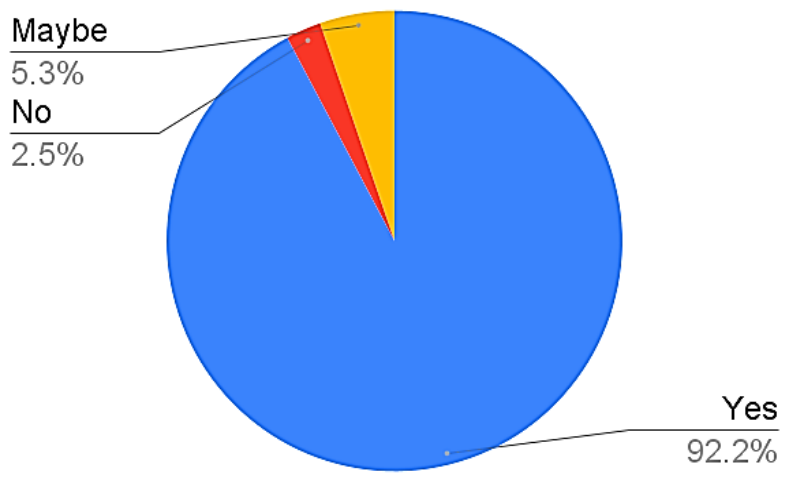

Figure 4. Long-term entrepreneurship intention.

\section{Entrepreneurial Sustainability Activity Findings}

\subsection{Relation of Multiple Intelligences to Entrepreneurship Intentions}

Considering the result of the survey and the eight types of multiple intelligences already mentioned, an ANN was designed using the neural network toolbox in the MATLAB program for the analysis of the entrepreneurial patterns in the short, medium, and long term. In particular, because there are several types of multiple intelligences, entrepreneurship patterns are related to all intelligence. It is important to clarify that the patterns were only analyzed concerning the intentions to undertake a project in the short, medium, and long term, i.e., the patterns were not analyzed for the results related to having doubts about undertaking or about not having the intention of starting an entrepreneurial project. This is because the results of this work will also be used as relevant information to improve the teaching-learning process about entrepreneurship and sustainability in various academic programs. Figure 5 shows the results of the pattern concerning the importance of multiple intelligences for short-term entrepreneurship. As can be seen, it appears that Intrapersonal Intelligence (MI6) was the most important (21.3\%) to all respondents, followed by Linguistic-Verbal Intelligence (MI2) and Interpersonal Intelligence (MI7), both with 19.8\%, whereas the least important intelligences were Naturalistic Intelligence (MI8), Bodily-Kinesthetic Intelligence (MI5), and Musical Intelligence (MI4). 


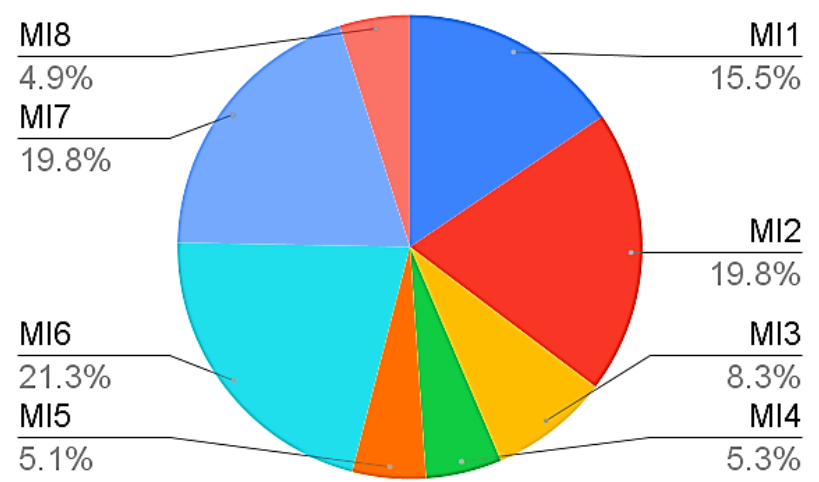

Figure 5. Relation of multiple intelligences for the detection of short-term entrepreneurship intention.

The medium-term entrepreneurship pattern was then analyzed. The results are shown in Figure 6. In this case, the intelligences most closely related to the intention of entrepreneurship were Interpersonal Intelligence (MI7), Intrapersonal Intelligence (MI6), and Linguistic-Verbal Intelligence (MI2), with 23.2\%, 22.8\%, and 21.1\%, respectively. The least affected intelligences were Naturalistic Intelligence (MI8) and Musical Intelligence (MI4), with $5.1 \%$ and $5.6 \%$, respectively.

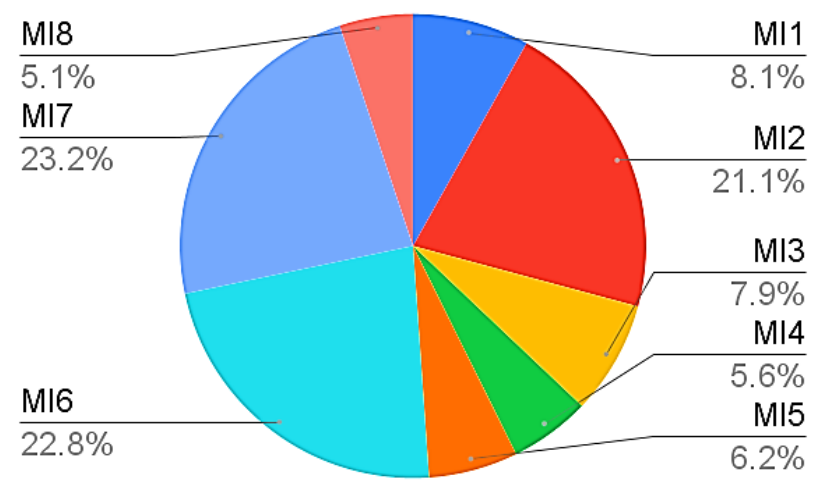

Figure 6. Relation of multiple intelligences for the detection of medium-term entrepreneurship intention.

Figure 7 shows the results for long-term entrepreneurship intent. In this case, the pattern of intelligences that best describe the intention of entrepreneurship remained almost constant, where the intelligences that had the least impact on the intention to undertake long-term sustainable projects were Logical-Mathematical Intelligence (MI1), Visual-Spatial Intelligence (MI3), Musical Intelligence (MI4), Bodily-Kinesthetic Intelligence (MI5), and Naturalistic Intelligence (MI8).

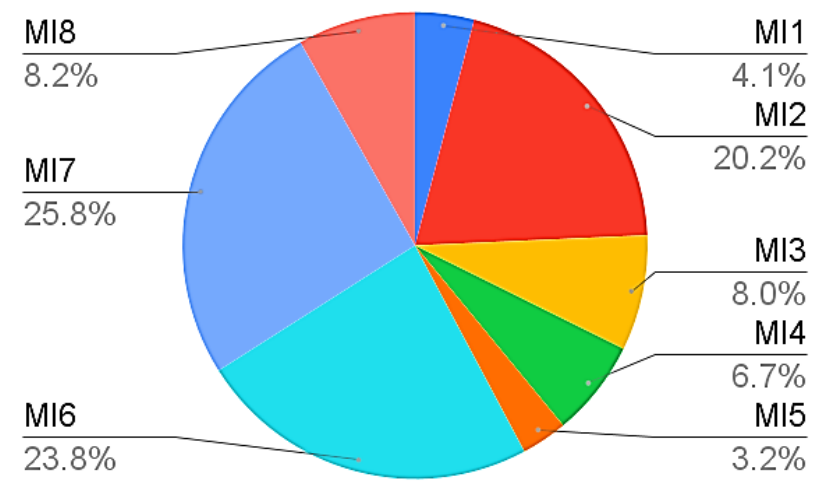

Figure 7. Relation of multiple intelligences for the detection of long-term entrepreneurship intention. 


\subsection{Pearson's Correlation Coefficient Results}

Then, the Pearson's correlation coefficient for each kind of intelligence was calculated for each condition of entrepreneurship intention (short, medium, and long term). The main objective of this mathematical method was to determine the specific intelligence that was most related (i.e., high correlation) to other types of intelligence $[54,55]$. In the same sense, the particular intelligence that was least related (i.e., low correlation) to the others was determined. Table 2 shows the final results related to the Pearson's correlation coefficients. In particular, Linguistic-Verbal Intelligence (MI2), Intrapersonal Intelligence (MI6), and Interpersonal Intelligence (MI7) presented the highest positive mean correlation with the other intelligences, at $\approx 0.964, \approx 0.932$, and $\approx 0.847$, respectively. This has significant implications. For example, when improving the performance (related to the self-evaluation) of some of the mentioned intelligences, the remaining intelligences increased, and on the other hand, by decreasing the performance of some of the intelligences (MI2, MI6, and MI7), the remaining intelligences also decreased their performance. An important aspect is that the standard deviation values for MI2 and MI6 were minimal $(\approx 0.072)$, which implies that the results are exact.

Table 2. Mean and variance of the Pearson's correlation coefficients for different entrepreneurship intentions.

\begin{tabular}{ccccccccccc}
\hline \multicolumn{10}{c}{ Short-Term Entrepreneurship Intention } \\
\hline & MI1 & MI2 & MI3 & MI4 & MI5 & MI6 & MI7 & MI8 & Overall Result \\
\hline Mean & 0.653 & 0.953 & 0.292 & 0.232 & 0.151 & 0.912 & 0.814 & 0.230 & 0.475 \\
Std. Dev. & 0.217 & 0.070 & 0.125 & 0.209 & 0.191 & 0.075 & 0.260 & 0.263 & 0.228 \\
\hline \multicolumn{8}{c}{ Medium-Term Entrepreneurship Intention } \\
\hline Mean & 0.832 & 0.963 & 0.193 & 0.225 & 0.121 & 0.932 & 0.834 & 0.213 & 0.568 \\
Std. Dev. & 0.114 & 0.040 & 0.189 & 0.356 & 0.258 & 0.055 & 0.152 & 0.368 & 0.198 \\
\hline \multicolumn{10}{c}{ Long-Term Entrepreneurship Intention } \\
Mean & 0.821 & 0.978 & 0.212 & 0.352 & 0.253 & 0.953 & 0.894 & 0.336 & 0.687 \\
Std. Dev. & 0.099 & 0.032 & 0.258 & 0.359 & 0.354 & 0.032 & 0.118 & 0.458 & 0.124 \\
\hline
\end{tabular}

The Pearson's correlation coefficient results also mean that the entrepreneurship intentions patterns shown above also present a hidden pattern related to the relationship of all intelligences. This hidden pattern is related to the three intelligences that presented the highest correlation. In addition, Table 2 show that, regardless of the time of intention to undertake an entrepreneurial project (i.e., short, medium, or long term), the actions planned to promote an entrepreneurship and sustainability program based on artificiality were robust over time.

\subsection{Performance Metrics of the ANN}

Considering the results shown above, a classifier was designed using the ANN. A classifier using an ANN is a mathematical structure that seeks to artificially reproduce the classification process carried out by the human brain by considering specific input information and generating a classification (output signal) based on patterns previously identified and learned patterns. In our case, the input information was related to multiple intelligences. Hypothetically, the classification structure asked the following question, "Considering the input information related to multiple intelligences, which known entrepreneurship intention pattern does it most resemble?" The foregoing aimed to discover a student's intention of sustainable entrepreneurship without asking them any direct question related to their intention of entrepreneurship, but rather, to infer the answer based on the evaluation of multiple intelligences. 
In particular, pattern classifiers use four performance metrics, including accuracy, precision, sensitivity, and specificity. When the values of these metrics are very close to $100 \%$, it means that the artificial structure used (i.e., ANN) for the classification of entrepreneurship intentions concerning multiple intelligences is adequate [56]. Table 3 shows performance metrics for short-, medium-, and long-term entrepreneurial intentions. As can be seen, the patterns found related to multiple intelligences almost perfectly described the entrepreneurial intention of the students. Furthermore, it can be seen that the classification error was extremely small $(\approx 0.72 \%)$. This has important implications since it allows us to ensure that the degrees of importance of multiple intelligences shown in Section 4.1 are correct.

Table 3. General performance metrics of the ANN for classifying entrepreneurship intentions.

\begin{tabular}{cccccc}
\hline & Accuracy & Precision & Sensitivity & Specificity & Classification Error \\
\hline Short-term & $99.72 \pm 0.25$ & $99.55 \pm 0.16$ & $99.98 \pm 1.25$ & $99.12 \pm 1.25$ & 0.45 \\
Medium-term & $99.02 \pm 0.52$ & $98.85 \pm 0.92$ & $99.90 \pm 0.05$ & $99.65 \pm 0.13$ & 0.53 \\
Long-term & $99.13 \pm 0.22$ & $98.29 \pm 0.85$ & $98.72 \pm 1.11$ & $98.27 \pm 0.42$ & 1.32 \\
\hline
\end{tabular}

In order to clarify the importance of the results shown in Table 3, let us imagine that we are measuring the multiple intelligences of a student group (e.g., 50 university students) at the beginning of their academic program. The ANN used in this study attempts to determine entrepreneurship patterns with an extremely small error probability. This way, activities related to entrepreneurship and sustainability can be planned and managed during the student's stay at the university (let us imagine about four years) based on the strengthening of the multiple intelligences that have the highest correlation coefficient. The aforementioned would aim to increase and strengthen the entrepreneurial and sustainable mentality through artificiality.

\subsection{Findings Analysis}

The results shown above allowed us to determine some important findings that clarify the relationship of multiple intelligences with entrepreneurship intentions in the short, medium, and long term. Some of the findings are mentioned and discussed below.

1. Three multiple intelligences always best represented entrepreneurship intention regardless of the temporal term. In particular, Linguistic-Verbal Intelligence (MI2), Intrapersonal Intelligence (MI6), and Interpersonal Intelligence (MI7) always showed the greatest impact on entrepreneurship intent. However, it is important to mention that Intrapersonal Intelligence (MI6) and Interpersonal Intelligence (MI7) increased their impact on the intention of long-term entrepreneurship, e.g., for the particular case of Interpersonal Intelligence (MI7), with 19.8\% for short term and $25.8 \%$ for long term, whereas Linguistic-Verbal Intelligence (MI2) remained almost constant in all terms.

2. Logical-Mathematical Intelligence (MI1) decreased its impact on entrepreneurship intention as the term became longer, e.g., $15.5 \%$ for short-term entrepreneurship intention, $8.1 \%$ for medium-term, and $4.1 \%$ for long-term.

3. Visual-Spatial Intelligence (MI3) maintained an almost constant impact on the intention of entrepreneurship for the short, medium, and long term (approximately $8 \%$ ). Similarly, Musical Intelligence (MI4) was approximately 5.6\%.

4. This is perhaps the finding that could generate the most surprise. The intention to undertake sustainable projects in the short, medium, and long term did not have a significant relationship with Naturalistic Intelligence (MI8). The above seems like a contradiction, i.e., how can it be that the intention to undertake a sustainable project does not have a high relationship with said intelligence? In this case, the results are not conclusive regarding the absence of this type of intelligence. Rather, the results show that a low level of this type of intelligence is required to carry out sustainable entrepreneurial projects. In the same sense, the results show that, with a low level 
regarding Naturalistic Intelligence (MI8) but a high level regarding Linguistic-Verbal Intelligence (MI2), Intrapersonal Intelligence (MI6), and Interpersonal Intelligence (MI7), it is possible to start a sustainable entrepreneurial project in the short, medium, and long term.

5. The types of intelligence that had the highest correlation were Linguistic-Verbal Intelligence (MI2), Intrapersonal Intelligence (MI6), and Interpersonal Intelligence (MI7). The foregoing can establish a very important rule for the planning and development of activities to promote entrepreneurship and sustainability, considering that by working directly with these types of intelligence, the remaining intelligences will be collaterally benefited. That is, resources can be optimized to strengthen all the multiple intelligences mentioned.

\subsection{Verification and Validation of the Artificiality}

The analysis scheme of entrepreneurship intention through an ANN is a good example of the artificiality applied to improve the results related to entrepreneurship. However, although such tools should be used more widely, they will not be unless end users can trust adaptive, nondeterministic, or complex artificial systems as support for intelligent decision-making. To increase trust in the artificiality applied to entrepreneurship, it is necessary to use verification and validation $(\mathrm{V} \& \mathrm{~V})$ methods. Nonetheless, these methods are well developed for general software development, whose ANN applications have some challenges to solve. However, there are also enough readily available alternative methods that allow V\&V of ANNs [57-60].

This has important implications for improving entrepreneurship and sustainability results using artificiality before real sustainable entrepreneurship projects developed by students. However, this task must also be interdisciplinary, because the concepts, techniques, tools, processes, and logic of different disciplines are required, among which we are business administration, engineering, psychology, and pedagogy, among others. Herewith, the V\&V method selected for the ANN will improve the results and, perhaps most importantly, increase the trust of the end-users (universities, institutions of the public, and private sectors).

\section{Impact of the Results for a Sustainable Future}

The results shown so far can be a relevant starting point for exploring the unforeseen regarding the minimal success or failure of various public and private policies concerning entrepreneurship in different sectors of the population (this manuscript emphasized the student sector). On the one hand, the findings allow us to think in depth about the relationship between entrepreneurship and multiple intelligences, because, according to our opinion and the literature consulted, there is no evidence of particular programs for the promotion of entrepreneurship and sustainability that directly consider the multiple intelligences of students. Although there are very specific case studies that analyze this argument in a general way, there is no clear evidence of its implementation. This could be the main cause of the very low levels of entrepreneurship and sustainability in various countries around the world. Notwithstanding, the results presented can be used as a resource to pave the way to a sustainable future. Considering the aforementioned, the following actions are proposed to pave the way to a sustainable future:

1. Artificiality in academic programs related to entrepreneurship and sustainability should be promoted, with the aim that students get involved and actively participate. In the first instance, students must carry out the designs and tests in an artificial way of their prototypes, products, services, processes, and business models based on creativity and innovation in order to minimize the risks, and then implement their innovations in the real world.

2. Various official and extracurricular activities should be carried out that help entrepreneurial mindsets and digital transformation based on the development of the multiple intelligences already mentioned. It is important to clarify that an en- 
trepreneurial mentality must be the goal, but the development of multiple intelligences must be the sustainable path and process in order for the entrepreneurial mentality to remain in the long term. In the case of promoting entrepreneurial mindsets without considering the development of multiple intelligences, there is a risk that the entrepreneurial spirit will be weak or limited in the short or medium term.

3. Through the development of multiple intelligences, the adaptation and sustainable growth of digital start-ups should be promoted. This prepares the entrepreneur, through the development and strengthening of multiple intelligences, to be resilient in a real business environment.

4. Activities that promote particular intelligences (e.g., Linguistic-Verbal Intelligence (MI2), Intrapersonal Intelligence (MI6), and Interpersonal Intelligence (MI7)) should be carried out to understand the role of networks and collaborative behavior in digital entrepreneurship.

5. The planning and development of official and extracurricular activities that help to understand the role of networks and collaborative behavior in social and environmentally responsible entrepreneurship should be encouraged. In particular, the development of mainly Natural Intelligence (MI8) and Interpersonal Intelligence (MI7) is encouraged.

\section{Conclusions}

In this paper, the analysis of the intention of entrepreneurship in the short, medium, and long term of Mexican university students in relation to sustainable projects was presented. The results related to entrepreneurship patterns and multiple intelligences can help with intelligent planning regarding the promotion of entrepreneurship and sustainability in the university community (although it is easily applicable to other sectors of the population). In particular, the results can help with the adequate design of academic and governmental programs, both in the public and private sectors, to catalyze the results of entrepreneurship and sustainability policies, which can help increase the competitiveness of an institution, department, or region. It is important to clarify that the instrument for data collection does not attempt to measure the level of intelligence of each person; rather, it is merely an instrument used as part of a self-assessment, which can add uncertainty to the results. This implies that a data collection instrument must be designed with greater fidelity (this is currently being worked on). It is also possible to use established statistical techniques, such as multiple regression rather than an $\mathrm{ANN}$, to relate test scores to entrepreneurship. However, it was decided to use this technique due to its technical advantages. Finally, finding 4 must be analyzed in-depth so that there is no confusion about the undertaking of sustainable projects and Naturalistic Intelligence (MI8). Last, because entrepreneurial indicators can widely change depending on several situations, the interdisciplinary approach proposed in this paper helps improve the understanding of the complex entrepreneurship phenomenon [61,62]. In addition, in relation to comparing our findings with other related works, quantitative and qualitative comparisons can be made. The results of the entrepreneurial intentions classifier (see Table 3) are better than those reported in [34]. On the other hand, the qualitative results strengthen the argument that entrepreneurial intentions have a clear relationship with multiple intelligences, although our work showed more specific results of this relationship. However, it is important to clarify that these results have a geographical, social, and temporal context, which may be an important variable that modifies these results.

Author Contributions: Conceptualization, J.A.L.-L., M.Á.P.-C., A.V.-G., V.M.R.-G. and H.N.M.-I.; methodology, J.A.L.-L., M.Á.P.-C., A.V.-G., V.M.R.-G. and H.N.M.-I.; software, J.A.L.-L. and M.Á.P.-C.; validation, J.A.L.-L., M.Á.P.-C., A.V.-G., V.M.R.-G. and H.N.M.-I.; formal analysis, J.A.L.-L., M.Á.P.-C. and A.V.-G.; investigation, J.A.L.-L., M.Á.P.-C., A.V.-G., V.M.R.-G. and H.N.M.-I.; resources, J.A.L.-L., M.Á.P.-C., A.V.-G., V.M.R.-G. and H.N.M.-I.; data curation, J.A.L.-L. and M.Á.P.-C.; writing-original draft preparation, J.A.L.-L.; writing—review and editing, J.A.L.-L., M.Á.P.-C., A.V.-G., V.M.R.-G. and H.N.M.-I.; visualization, J.A.L.-L. and M.Á.P.-C.; supervision, J.A.L.-L.; project administration, J.A.L.-L. All authors have read and agreed to the published version of the manuscript. 
Funding: This research received no external funding.

Institutional Review Board Statement: Ethical review and approval were waived for this study due to the fact that we used anonymous data that were not traceable to individuals at any time and the research does not deal with vulnerable groups or sensitive issues.

Informed Consent Statement: Informed consent was obtained from all subjects involved in the study.

Data Availability Statement: Not applicable.

Conflicts of Interest: The authors declare no conflict of interest.

\section{References}

1. McMullen, J.S.; Bergman, B.J. Social Entrepreneurship and the Development Paradox of Prosocial Motivation: A Cautionary Tale. Strateg. Entrepreneurship J. 2017, 11, 243-270. [CrossRef]

2. Walzer, N. Introduction: Entrepreneurship in Community Development. Community Dev. J. 2004, 35, 1-4. [CrossRef]

3. Muñoz, P.; Kimmitt, J. Rural entrepreneurship in place: An integrated framework. Entrep. Reg. Dev. 2019, 31, 842-873. [CrossRef]

4. Sarma, S.K. Investigating Failed Social Entrepreneurship: A 'Process Research' Perspective. In Methodological Issues in Social Entrepreneurship Knowledge and Practice; Majumdar, E.S., Meethal, R., Eds.; Springer: Singapore; pp. 79-93. [CrossRef]

5. Larsson, A. The 4 I's of Entrepreneurship: A Study of the Entrepreneurial Perspectives behind A Failed Large-Scale Distributed Research Infrastructure. Entrepreneurship Res. J. 2018, 9, 20170115. [CrossRef]

6. Anand, A.; Walsh, I. The four stages of the knowledge sharing process in SMEs. Int. J. Entrep. Innov. Manag. 2020, 24, 465. [CrossRef]

7. Spigel, B.; Harrison, R. Toward a process theory of entrepreneurial ecosystems. Strateg. Entrep. J. 2017, 12, 151-168. [CrossRef]

8. Salhieh, S.M.; Al-Abdallat, Y. Technopreneurial Intentions: The Effect of Innate Innovativeness and Academic Self-Efficacy. Sustainability 2022, 14, 238. [CrossRef]

9. Galanakis, K.; Giourka, P. Entrepreneurial path: Decoupling the complexity of entrepreneurial process. Int. J. Entrep. Behav. Res. 2017, 23, 317-335. [CrossRef]

10. Niesten, E.; Jolink, A.; Lopes de Sousa Jabbour, A.B.; Chappin, M.; Lozano, R. Sustainable collaboration: The impact of governance and institutions on sustainable performance. J. Clean. Prod. 2017, 155, 1-6. [CrossRef]

11. Ortiz-de-Mandojana, N.; Bansal, P. The long-term benefits of organizational resilience through sustainable business practices. Strateg. Manag. J. 2015, 37, 1615-1631. [CrossRef]

12. Hameed, I.; Irfan, Z. Entrepreneurship education: A review of challenges, characteristics and opportunities. Entrep. Educ. 2019, 2, 135-148. [CrossRef]

13. Alvarez de Mon, I.; Merladet, J.; Núñez-Canal, M. Social Entrepreneurs as Role Models for Innovative Professional Career Developments. Sustainability 2021, 13, 13044. [CrossRef]

14. Barba-Sánchez, V.; Atienza-Sahuquillo, C. Entrepreneurial intention among engineering students: The role of entrepreneurship education. Eur. Res. Manag. Bus. Econ. 2018, 24, 53-61. [CrossRef]

15. Mattingly, E.S. Dependent Variables in Entrepreneurship Research. J. Entrepreneurship 2015, 24, 223-241. [CrossRef]

16. Wu, J.; Alshaabani, A.; Rudnák, I. Testing the Influence of Self-Efficacy and Demographic Characteristics among International Students on Entrepreneurial Intention in the Context of Hungary. Sustainability 2022, 14, 1069. [CrossRef]

17. Bordei, S. How Can One Possibly Determine the Multiple Intelligences? J. Plus Educ. 2017, 18, 204-212. [CrossRef]

18. Martin, J. Intelligences which make you successful. In Profiting from Multiple Intelligences in the Workplace; Routledge: London, 2009; pp. 75-104. [CrossRef]

19. Escobar, M.; Vargas, D. Multiple Intelligences and Work Styles. SSRN Elect. J. 2021, 1-15. [CrossRef]

20. Sabahi, S.; Parast, M.M. The impact of entrepreneurship orientation on project performance: A machine learning approach. Int. J. Prod. Econ. 2020, 226, 107621. [CrossRef]

21. Olafsen, A.H.; Nilsen, E.R.; Smedsrud, S.; Kamaric, D. Sustainable development through commitment to organizational change: The implications of organizational culture and individual readiness for change. J. Workplace Learn 2020, 33, 180-196. [CrossRef]

22. Abbas, J.; Zhang, Q.; Hussain, I.; Akram, S.; Afaq, A.; Shad, M.A. Sustainable Innovation in Small Medium Enterprises: The Impact of Knowledge Management on Organizational Innovation through a Mediation Analysis by Using SEM Approach. Sustainability 2020, 12, 2407. [CrossRef]

23. Hughes, M. Resistance and organizational change readiness. In Managing and Leading Organizational Change; Routledge: London, 2018; pp. 219-236. [CrossRef]

24. Mavlutova, I.; Krastinšs, M.; Hermanis, J.; Lešinskis, K. Student-centered methods in entrepreneurship education to increase entrepreneurial intentions of students. Litt. Scr. 2019, 12, 1-19. [CrossRef]

25. Lewaru, T.S. Factors Affecting Entrepreneurial Intentions Among College Student. Tangible J. 2021, 5, 79-86. [CrossRef]

26. Padilla-Angulo, L. Student associations and entrepreneurial intentions. Stud. High. Educ. 2017, 44, 45-58. [CrossRef]

27. Monllor, J.; Soto-Simeone, A. The impact that exposure to digital fabrication technology has on student entrepreneurial intentions. Int. J. Entrep. Behav. Res. 2019, 26, 1505-1523. [CrossRef] 
28. Zampetakis, L.A.; Kafetsios, K.; Bouranta, N.; Dewett, T.; Moustakis, V.S. On the relationship between emotional intelligence and entrepreneurial attitudes and intentions. Int. J. Entrepreneurial Behav. Res. 2009, 15, 595-618. [CrossRef]

29. Tiwari, P.; Bhat, A.K.; Tikoria, J. The role of emotional intelligence and self-efficacy on social entrepreneurial attitudes and social entrepreneurial intentions. J. Soc. Entrep. 2017, 8, 165-185. [CrossRef]

30. Binti Omar, S.N.; Hassan, R.A. The Effect of Emotional Intelligence and Entrepreneurial Attitude on Entrepreneurial Intention. Arab. J. Bus. Manag. Rev. 2016, 5, 1-10. [CrossRef]

31. Rodrigues, A.P.; Jorge, F.E.; Pires, C.A.; António, P. The contribution of emotional intelligence and spirituality in understanding creativity and entrepreneurial intention of higher education students. Educ. Train. 2019, 61, 870-894. [CrossRef]

32. Miao, C.; Humphrey, R.H.; Qian, S.; Pollack, J.M. Emotional intelligence and entrepreneurial intentions: An exploratory meta-analysis. Career Dev. Int. 2018, 23, 497-512. [CrossRef]

33. Yıldırım, F.; Trout, I.Y.; Hartzell, S. How Are Entrepreneurial Intentions Affected by Emotional Intelligence and Creativity? Period. Polytech. Soc. Manag. 2019, 27, 59-65. [CrossRef]

34. Wei, Y.; Lv, H.; Chen, M.; Wang, M.; Heidari, A.A.; Chen, H.; Li, C. Predicting Entrepreneurial Intention of Students: An Extreme Learning Machine With Gaussian Barebone Harris Hawks Optimizer. IEEE Access 2020, 8, 76841-76855. [CrossRef]

35. Arshi, T.A.; Islam, S.; Gunupudi, N. Predicting the effect of entrepreneurial stressors and resultant strain on entrepreneurial behaviour: An SEM-based machine-learning approach. Int. J. Entrepreneurial Behav. Res. 2021, 27, 1819-1848. [CrossRef]

36. Dharma Tuah Putra Nasution, M.; Putera Utama Siahaan, A.; Rossanty, Y.; Aryza, S. Entrepreneurship Intention Prediction using Decision Tree and Support Vector Machine. In Proceedings of the Joint Workshop KO2PI and The 1st International Conference on Advance \& Scientific Innovation, Medan, Indonesia, April 2018; pp. 135-148. [CrossRef]

37. Gardner, H.; Hatch, T. Multiple Intelligences Go to School: Educational Implications of the Theory of Multiple Intelligences. Educ. Res. 1989, 18, 4. [CrossRef]

38. Gardner, H. Taking a multiple intelligences (MI) perspective. Behav. Brain Sci. 2017, 40, e203. [CrossRef] [PubMed]

39. Gardner, H. Probing More Deeply into The Theory of Multiple Intelligences. NASSP Bull. 1996, 80, 1-7. [CrossRef]

40. Malekian, F.; Maleki, Z. A Survey on Relation Between the Amount of Multiple Intelligences (Gardner) and Entrepreneurship Sense Among University Students. Procedia Soc. Behav. Sci. 2012, 51, 891-896. [CrossRef]

41. Hastuti, I.; Purnomo, S.; Lestari, W. The guidance of technopreneurship using expert system computing approach based on entrepreneurial values and multiple intelligences. Int. J. Econ. Bus. Account. Res. 2018, 2, 27-35. [CrossRef]

42. Cooper, C. Intelligence and Human Abilities: Structure, Origins and Applications; Routledge: London, 2015. [CrossRef]

43. Pearson, F. Intelligence and human abilities. Structure, origins and applications. Educ. Psychol. Pract. 2016, 32, 210-211. [CrossRef]

44. Visser, B.A.; Ashton, M.C.; Vernon, P.A. Beyond g: Putting multiple intelligences theory to the test. Intelligence 2006, 34, 487-502. [CrossRef]

45. Yao, G.; Lei, T.; Zhong, J. A review of Convolutional-Neural-Network-based action recognition. Pattern Recognit. Lett. 2019, 118, 14-22. [CrossRef]

46. Abiodun, O.I.; Kiru, M.U.; Jantan, A.; Omolara, A.E.; Dada, K.V.; Umar, A.M.; Linus, O.U.; Arshad, H.; Ka-zaure, A.A.; Gana, U. Comprehensive Review of Artificial Neural Network Applications to Pattern Recognition. IEEE Access 2019, 7, 158820-158846. [CrossRef]

47. Spratling, M.W. Explaining away results in accurate and tolerant template matching. Pattern Recognit. 2020, $104,107337$. [CrossRef]

48. Meher, S.K. Explicit rough-fuzzy pattern classification model. Pattern Recognit. Lett. 2014, 36, 54-61. [CrossRef]

49. Zoppoli, R. Neural networks: Current applications. Eng. Appl. Artif. Intell. 1993, 6, 77. [CrossRef]

50. Karaca, Y. Case study on artificial neural networks and applications. Appl. Math. Sci. 2016, 10, 2225-2237. [CrossRef]

51. Khudhair, R. Applications of Artificial Neural Networks in E-Learning Personalization. Int. J. Comput. Appl. 2017, 158, 37-39. [CrossRef]

52. Hoda, N.; Ahmad, N.; Gupta, S.L.; Alam, M.M.; Ahmad, I. Application of Entrepreneurial Intention Model in Comparative International Entrepreneurship Research: A Cross-Cultural Study of India and Saudi Arabia. Sustainability 2021, $13,13369$. [CrossRef]

53. Simon, H.A. The Science of Design: Creating the Artificial. In The Sciences of the Artificial; MIT Press, 2019; Available online: https:/ / doi.org/10.7551/mitpress/12107.003.0008 (accessed on 10 December 2021).

54. Pearson, K. Determination of the coefficient of correlation. Science 1909, 30, 23-25. [CrossRef]

55. Rahman, M.; Zhang, Q. Comparison among pearson correlation coefficient tests. Far East J. Math. Sci. 2015, 99, 237-255. [CrossRef]

56. Deep, R. Probability and Statistics: With Integrated Software Routines; Academic: Cambridge, MA, USA, 2006; Available online: https:/ / www.elsevier.com/books/probability-and-statistics/deep/978-0-12-369463-8 (accessed on 10 December 2021).

57. Menzies, T.; Pecheur, C. Verification and Validation and Artificial Intelligence. Adv. Comput. 2005, 65, 153-201. [CrossRef]

58. Preece, A.; Shinghal, R.; Batarekh, A. Verifying expert systems: A logical framework and a practical tool. Expert Syst. Appl. 1992, 5, 421-436. [CrossRef]

59. Preece, A. Principles and practice in verifying rule-based systems. Knowl. Eng. Rev. 1992, 7, 115-141. [CrossRef]

60. Jamroga, W.; Knapik, M.; Kurpiewski, D.; Mikulski, Ł. Approximate verification of strategic abilities under imperfect information. Artif. Intell. 2019, 277, 103172. [CrossRef] 
61. Burger-Helmchen, T. Unusual entrepreneurs for unusual entrepreneurship. Int. J. Soc. Entrepreneurship Innov. $2020,5,241$. [CrossRef]

62. Gartner, W.B. A Conceptual Framework for Describing the Phenomenon of New Venture Creation. Acad. Manage. Rev. 1985, 10, 696-706. [CrossRef] 